\title{
APPLICATION OF THE BAYESIAN DSGE MODEL TO THE INTERNATIONAL TOURISM SECTOR: EVIDENCE FROM THAILAND'S ECONOMIC CYCLE
}

\author{
SATAWAT WANNAPAN, CHUKIAT CHAIBOONSRI \& SONGSAK SRIBOONCHITTA \\ Puay Ungphakorn Centre of Excellence in Econometrics, Faculty of Economics, Chiang Mai University, Thailand
}

\begin{abstract}
This paper is intended for clarifying and forecasting the dynamic structural components inside the relationship between tourism income and economic cycling parameters. Quarterly time-series variables such as Thailand tourism revenues and gross domestic products are collected during the period of 1997 to 2016. The simulation methods using the Marko Chain Monte-Carlo approach (MCMC) and Metropolis-Hasting algorithm (MH) which are Bayesian seasonal unit-root testing (B-HEGY), Markov Switching Bayesian VAR (MSBVAR), and Bayesian Dynamic Stochastic General Equilibrium modelling (B-DSGE). Empirically, the results estimated by the MSBVAR model strongly confirm that the business cycles of Thailand tourism are divided into two stages based on business cycle facts, which are in high-season and low-season periods. From the results of the B-DSGE model, the outcomes represent both capital and labour factors of tourism sectors in high-seasonal moments that are positive for Thailand economic expansions. This can be explained that there is no anxiety and any increments of tourism revenues that could lead to systematically boot up employments in economy system. Tourism policies should be implemented for extending high-season moments for as long as possible. Conversely, the results of the dynamic simulated model show that low-seasonal periods negatively cause fluctuations in the economic system, especially the sudden shut down of labour sectors. Therefore, training programs for skilled labour improving in service sectors and technology adaptations should be intensively activated. Accordingly, changing low-season periods to high-seasonal moments is the main purpose that policy makers should focus on.
\end{abstract}

Keywords: Thailand tourism revenue, RBC model, simulation models, Bayesian inference, BayesianHEGY test, Bayesian-MSVAR model, Bayesian-DSGE model.

\section{INTRODUCTION}

The tourism sector of Thailand has brought money to cities and provided an enormous amount of jobs for both urban and local residents, further benefiting the destination [1]. Generally, the total percentage of tourism contributions to Thailand GDP has increased from $14.5 \%$ to $20.6 \%$ during 1997 to 2016 [2]. Obviously, tourism is recently driving the expansion rates of domestic products and becoming the backbone income for the country.

To theoretically address the topic regarding to the dynamic impact of tourism linked with economic systems, Real Business Cycle theory (RBC), provides successful expressions from recession and boom situations which make the notable contribution of fluctuations in economic activities that are consonant with competitive general equilibrium environments which all agents are rational optimizers [3]. To empirically research, the highlight econometric estimation which presented in this paper is the Dynamic Stochastic General Equilibrium model (DSGE). This model is defined as the "new neoclassical synthesis" that combined the real neoclassical business cycle framework of rational optimization, the new Keynesian framework of market imperfections, and the idea of long-run monetary policy. Superbly, it can dominate the problem of misspecification and vulnerability in traditional macro-econometric models. In addition, with powerful tools like Bayesian inference and Monte Carlo Simulation, we will have the solution to extend the ability of parametric estimating in the DSGE model since the lack of time-series observations, especially from 
Thailand tourism information. Accordingly, this paper is conducted to study on multieconometric analyses, and its estimated results will clarify a new aspect of forecasting in tourism economics.

Currently, Bayesian inference is being employed to clarify the complex parametric estimation in several fields, for instance, Takaishi [4] and Türkcan et al. [5]. To apply Bayesian analysis in multi-econometric estimations such as the HEGY seasonal unit-root test, Markov Switching calculating (MS-model), and the DSGE analysis, these combinations are rare. Historically, in classically statistical inference, the HEGY test invented by Hylleberg et al. [6] has been employed to investigate the seasonal stationary trend of time-series data in many fields. After considering the Markov switching model based on Bayesian inference, this approach is interesting for many researchers to econometrical clarifying the types of regime cycles in time-series information, for instance, Bildirici and Ersin [7] and Chaitip and Chaiboonsri [8]. Moreover, it is found that MS-model applying which based on Bayesian statistics is infrequent in tourism research, especially, Thailand tourism indexes. This paper is proposed to computationally use the MS-model to classify switching regimes in Thailand tourism trends. Regarding to DSGE model, Fernández-Villaverde [9] and Kliem and Uhlig [10] applied it to clarify the dynamic parameters in financial economics. Consequently, it is sensible that DSGE model which based on the Bayesian way can be employed to dynamically predict Thailand tourism parameters. Finally, the empirical results would be the important sign that can evidently picture the upcoming occurrences of tourism demands and supplies for precisely activating sustainable tourism policies in Thailand.

\section{THE OBJECTIVES OF RESEARCH}

To address the issues of real tourism cycling trends, the first object is mentioned about employ HEGY seasonal unit root testing to clarify the most suitable type of stationary testing for seasonal data sets. For the second object, the switching regime estimation called MSmodel is employed to investigate the real economic cycle of Thailand tourism incomes. To consider dynamic stochastic impacts issue from tourism incomes which related to economic growth, the third object is aimed to apply the DSGE model for systematic adjustment in Thailand's economic structural expressing.

\section{CALIBRATED PRIOR FOR MODEL SETTING}

Since it is not like the traditional way of statistics (objective thinking), Bayesian inference is defined as "modern" in econometrics, which is called subjective thinking. Conceptually, the models' posteriors are relied on "belief" or "prior", which can be generated from truth and academic references. For the seasonal unit-root test, the prior is assigned to state that there is a seasonal movement in Thailand tourism during 20 years. According to the data regimes classification, the prior is set to prove that there are fluctuated trends depended on real business cycles and numerically collect them. At last, in the section of dynamic forecasting, sensibly calibrated parameters in the DSGE model are set as $\alpha, \rho, \tau, \beta, \delta, \psi, \theta, \varepsilon$, and $\mu$ is fixed to be the initial values for estimating simulated posteriors, which were in the normal situation, expanding periods, and recessions. The initial parameters were represented in Table 1 which illustrated the details of representatively calibrated parameters are as follows. We firstly set $\alpha$ which implies the expansion rates of Thailand average GDP, including $2.4 \%$ per year for the normal situation referred to Tanboon [11], 2.54\% for boom periods, and $2.17 \%$ for recessions. We set $\rho$ and $\tau$ to be fixed, which are 0.95 and 0.025 , respectively [11]. For the discount factor $\beta$, we set $\beta$ as $=1.03-0.25=0.9926$, which refers to a steady-state annualized real interest rate 3\% per year [22]. Furthermore, the physical depreciation rate is based theoretically on the rate at steady state, which equals $2.5 \%$ per year for all situations [12]. 
Table 1: Calibrated parameters for prior distributions.

\begin{tabular}{|c|l|c|c|c|}
\hline Symbol & Description & $\begin{array}{c}\text { Values } \\
\text { (normal } \\
\text { situations) }\end{array}$ & $\begin{array}{c}\text { Values } \\
\text { (high-season } \\
\text { situations) }\end{array}$ & $\begin{array}{c}\text { Values } \\
\text { (low-season } \\
\text { situations) }\end{array}$ \\
\hline$\alpha$ & GDP growth rate (2.4\% per year) & 0.0240 & 0.0254 & 0.0217 \\
\hline$\rho$ & The coefficient of persistence shocks & 0.9500 & 0.9500 & 0.9500 \\
\hline$\tau$ & $\begin{array}{l}\text { The coefficient of cross-persistence } \\
\text { shocks }\end{array}$ & 0.0250 & 0.0250 & 0.0250 \\
\hline$\beta$ & $\begin{array}{l}\text { The discount factor (real interest rate } \\
3 \% \text { per year) }\end{array}$ & 0.9926 & 0.9926 & 0.9926 \\
\hline$\delta$ & Physical capital depreciation & 0.0250 & 0.0250 & 0.0250 \\
\hline$\varphi$ & Tourism ratios to nominal GDP & 0.0817 & 0.0865 & 0.0738 \\
\hline$\theta$ & The disutility of labour & 1.0000 & 1.0000 & 1.0000 \\
\hline$\varepsilon$ & The variance of persistence shocks & 0.0000 & 0.0000 & 0.0000 \\
\hline$\mu$ & $\begin{array}{l}\text { The variance of cross-persistence } \\
\text { shocks }\end{array}$ & 0.0000 & 0.0000 & 0.0000 \\
\hline
\end{tabular}

Additionally, the factor of tourism income ratios affecting to GDP, ${ }^{\varphi}$, is calculated from the data sets, which is collected from World Bank Database, the Bank of Thailand, and Thomson Reuters Database. The ratios are $8.17 \%$ per GDP annually for the normally economic system, $8.65 \%$ per GDP for the boom situations, and $7.38 \%$ for recessions. Moreover, the disutility of labour is assumed to equal one, which implies there is no scaling for the disutility of labour supply [11]. Lastly, the factors of shocks, $\varepsilon$ and $\mu$, are theoretically fixed to be zero [12].

\section{EMPIRICAL RESULTS OF RESEARCH}

\subsection{The Bayesian HEGY seasonal unit root test (BHEGY test)}

Estimating the BHEGY model, the data sets such as quarterly tourism incomes and Thailand GDP were investigated to ensure that they contained seasonally structural trends. Obviously, the estimated results shown in Table 2 strongly indicate that the seasonal unit-root test is the most suitable method for interpreting these quarterly trends.

Table 2: BHEGY unit-root testing results presentation table.

\begin{tabular}{|l|c|l|r|r|l|l|}
\hline Variables & Model & Hypothesis (prior) & Iterations & Posterior & Bayesian factors & Result \\
\hline \multirow{2}{*}{$\begin{array}{l}\text { Thailand } \\
\text { GDP }\end{array}$} & Model 1 & $\begin{array}{l}\left(M_{1}\right) \text { : Seasonally } \\
\text { structural unit root }\end{array}$ & 11,000 & $2.63 \mathrm{e}^{66}$ & Strong evidence \\
\cline { 2 - 7 } & Model 2 & $\begin{array}{l}\left(M_{2}\right): \text { Normally } \\
\text { structural unit root }\end{array}$ & 11,000 & $3.8 \mathrm{e}^{-67}$ & $\begin{array}{l}\text { Data has } \\
\text { seasonal } \\
\text { unit root }\end{array}$ \\
\hline $\begin{array}{l}\text { Thailand } \\
\text { tourism } \\
\text { incomes }\end{array}$ & Model 1 & $\begin{array}{l}\left(M_{1}\right) \text { : Seasonally } \\
\text { structural unit root }\end{array}$ & 191,600 & $3.88 \mathrm{e}^{43}$ & Strong evidence \\
\cline { 2 - 6 } & Model 2 & $\begin{array}{l}\left(M_{2}\right): \text { Normally } \\
\text { structural unit root }\end{array}$ & 78,100 & $2.58 \mathrm{e}^{-44}$ & $\begin{array}{l}\text { Data has } \\
\text { seasonal } \\
\text { unit root }\end{array}$ \\
\hline
\end{tabular}




\subsection{Expected durations of regimes by the MSBVAR model}

The results were found in the numbers of expected duration regimes, which are the expansions (boom periods) and depressions (recession times) during 20 years. In other words, the bivariate Bayesian Markov switching model indicated that there were more expansion cycles than recessing periods along the trend of tourism incomes that affected the economic structure, which were 54 and 24 times, respectively.

\subsection{The explanation of Bayesian DSGE model investigation}

There are three possible cases such as normal economic movements, booming situations, and recessions. The results of BDSGE testing are represented in Tables 3, 4, and 5, respectively. For explaining the prior distributions and the remained eight parameters were in line with the literature. General principles guiding the choice of the distributions are as follows: the beta distribution is employed to clarify parameters bounded between zero and unity, and the gamma distribution is used to describe parameters assumed to be positive values. Speaking to the posterior distributions, the results are drawn from total of 6,000 simulated observations which obtained through the Metropolis-Hastings sampling algorithm. Two independent chains and convergence criteria were also achieved [23]. Accordingly, the comparison between prior and posterior means for three situational types is displayed in Figs 1, 2, and 3, respectively.

Considering speedy adjustments of economy were theoretically based on the RBC model and their details are shown in Figs 4, 5, and 6, respectively. Focusing on prediction in the next ten years, the results of the impulse responses clearly picture the estimated structural parameters such as economic growth rate (y), physical capital in tourism sectors $(\mathrm{k})$, consumptions in tourism (c), stochastic technological shocks (a), and shocks affecting incorporated technological progress (b) which are not converged to the equilibrium in all circumstances when tourism incomes have impacted the economic system. Comparing the parameters in three situations, it is evidence that the economic expansion rate (y) in the normal case is lack of truth expression. In other words, when the fluctuated trends in tourism are not mentioned, the growth rate is lower than the counterparts in both booming and recession cases. Obviously, the impulse response line states that the economic growth rate in booming cases is a longer positive impact on the economic system than the recession cases, which are approximately more than 4 years in booming situations and lower than 4 years for economic expansion in recession cases.

According to the supply side, physical capital in Thailand tourism sectors (k), the results pictured in the figures state that there is no equilibrium convergence in all of three cases during the next ten years. In cases of labour supplies $(\mathrm{h})$, it is real that booming periods are the great benefits for skilled-labour growth in tourism sectors, which are nearly 8 years for positive skilled-labour employments. On the other hand, there are approximately 5 years for skilled-labour growth.

Speaking to the demand side, consumptions in tourism sectors (c), the results present that the tourism demand in Thailand is similar to all three situations. This means that the impulse response line of tourism demand is pictured to increase in the next ten years. Consequently, this can be concluded that the demand side is relied on exogenous factors rather than internally structural factors. However, it is different in the tourism supply side. It is mostly depended on internal factors rather than exogenous cases. 
Table 3: Prior and posterior distributions in normally economic cycles presentation.

\begin{tabular}{|l|c|c|c|c|c|}
\hline Parameters & \multicolumn{2}{|c|}{$\begin{array}{c}\text { Prior } \\
\text { distribution }\end{array}$} & \multicolumn{3}{|c|}{ Posterior distribution } \\
\hline Description & $\begin{array}{c}\text { Prior } \\
\text { Mean }\end{array}$ & $\begin{array}{c}\text { Posterior } \\
\text { Mean }\end{array}$ & $\begin{array}{c}\text { Confident } \\
\text { interval 5\% }\end{array}$ & $\begin{array}{c}\text { Confident } \\
\text { interval 90\% }\end{array}$ \\
\hline GDP growth rate & $\alpha$ & 0.003 & 0.0029 & 0.0019 & 0.0044 \\
\hline Discount factor & $\beta$ & 0.990 & 0.9902 & 0.9884 & 0.9927 \\
\hline Physical capital depreciation & $\delta$ & 0.037 & 0.0370 & 0.0264 & 0.0488 \\
\hline Tourism ratios to nominal GDP & $\varphi$ & 1.750 & 1.8160 & 1.6789 & 2.0259 \\
\hline Persistence shocks & $\rho$ & 0.950 & 0.9225 & 0.9216 & 0.9233 \\
\hline Disutility of labor & $\theta$ & 3.000 & 2.5894 & 2.0247 & 3.4857 \\
\hline Cross-persistence shocks & $\tau$ & 0.030 & 0.0771 & 0.0764 & 0.0779 \\
\hline $\begin{array}{l}\text { Variance-covariance of } \\
\text { innovations }\end{array}$ & $\varepsilon$ & 0.010 & 0.0138 & 0.0138 & 0.0142 \\
\hline
\end{tabular}

Table 4: Prior and posterior distributions in booming cycles presentation.

\begin{tabular}{|l|c|c|c|c|c|}
\hline Parameters & \multicolumn{2}{|c|}{$\begin{array}{c}\text { Prior } \\
\text { distribution }\end{array}$} & \multicolumn{3}{|c|}{ Posterior distribution } \\
\hline Description & $\begin{array}{c}\text { Prior } \\
\text { Mean }\end{array}$ & $\begin{array}{c}\text { Posterior } \\
\text { Mean }\end{array}$ & $\begin{array}{c}\text { Confident } \\
\text { interval 5\% }\end{array}$ & $\begin{array}{c}\text { Confident } \\
\text { interval 90\% }\end{array}$ \\
\hline GDP growth rate & $\alpha$ & 0.003 & 0.0034 & 0.0021 & 0.0049 \\
\hline Discount factor & $\beta$ & 0.990 & 0.9902 & 0.9877 & 0.9931 \\
\hline Physical capital depreciation & $\delta$ & 0.050 & 0.0413 & 0.0060 & 0.0682 \\
\hline Tourism ratios to nominal GDP & $\varphi$ & 1.200 & 1.1816 & 1.0090 & 1.3233 \\
\hline Persistence shocks & $\rho$ & 0.950 & 0.9238 & 0.9231 & 0.9243 \\
\hline Disutility of labor & $\theta$ & 3.000 & 2.6560 & 2.1584 & 3.1866 \\
\hline Cross-persistence shocks & $\tau$ & 0.030 & 0.0752 & 0.0752 & 0.0764 \\
\hline $\begin{array}{l}\text { Variance-covariance of } \\
\text { innovations }\end{array}$ & $\varepsilon$ & 0.010 & 0.0146 & 0.0144 & 0.0152 \\
\hline
\end{tabular}

Table 5: Prior and posterior distributions in booming cycles presentation.

\begin{tabular}{|l|c|c|c|c|c|}
\hline Parameters & \multicolumn{2}{|c|}{$\begin{array}{c}\text { Prior } \\
\text { distribution }\end{array}$} & \multicolumn{3}{|c|}{ Posterior distribution } \\
\hline Description & $\begin{array}{c}\text { Prior } \\
\text { Mean }\end{array}$ & $\begin{array}{c}\text { Posterior } \\
\text { Mean }\end{array}$ & $\begin{array}{c}\text { Confident } \\
\text { interval 5\% }\end{array}$ & $\begin{array}{c}\text { Confident } \\
\text { interval 90\% }\end{array}$ \\
\hline GDP growth rate & $\alpha$ & 0.003 & 0.0034 & 0.0021 & 0.0049 \\
\hline Discount factor & $\beta$ & 0.990 & 0.9902 & 0.9877 & 0.9931 \\
\hline Physical capital depreciation & $\delta$ & 0.050 & 0.0413 & 0.0060 & 0.0682 \\
\hline Tourism ratios to nominal GDP & $\varphi$ & 1.200 & 1.1816 & 1.0090 & 1.3233 \\
\hline Persistence shocks & $\rho$ & 0.950 & 0.9238 & 0.9231 & 0.9243 \\
\hline Disutility of labor & $\theta$ & 3.000 & 2.6560 & 2.1584 & 3.1866 \\
\hline Cross-persistence shocks & $\tau$ & 0.030 & 0.0752 & 0.0752 & 0.0764 \\
\hline $\begin{array}{l}\text { Variance-covariance of } \\
\text { innovations }\end{array}$ & $\varepsilon$ & 0.010 & 0.0146 & 0.0144 & 0.0152 \\
\hline
\end{tabular}



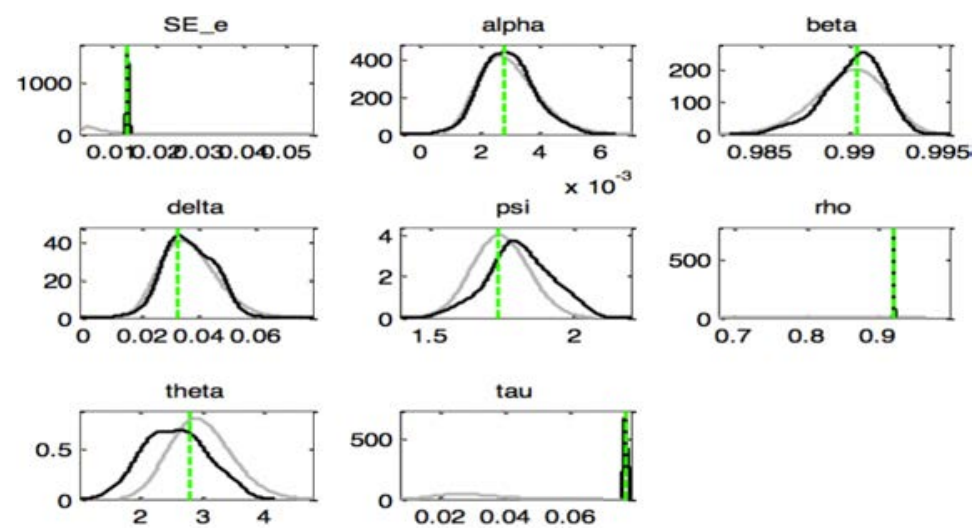

Figure 1: Priors and posteriors in normal economy.
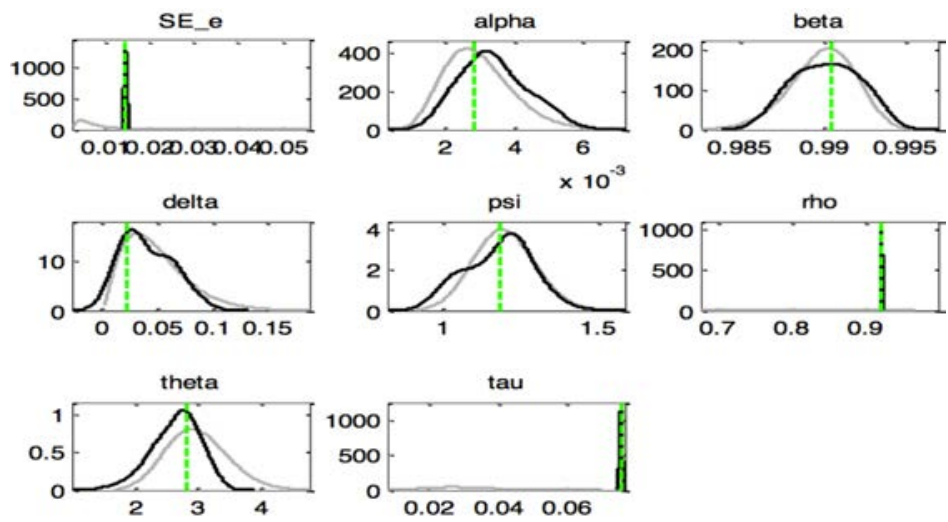

Figure 2: Priors and posteriors in boom economy.
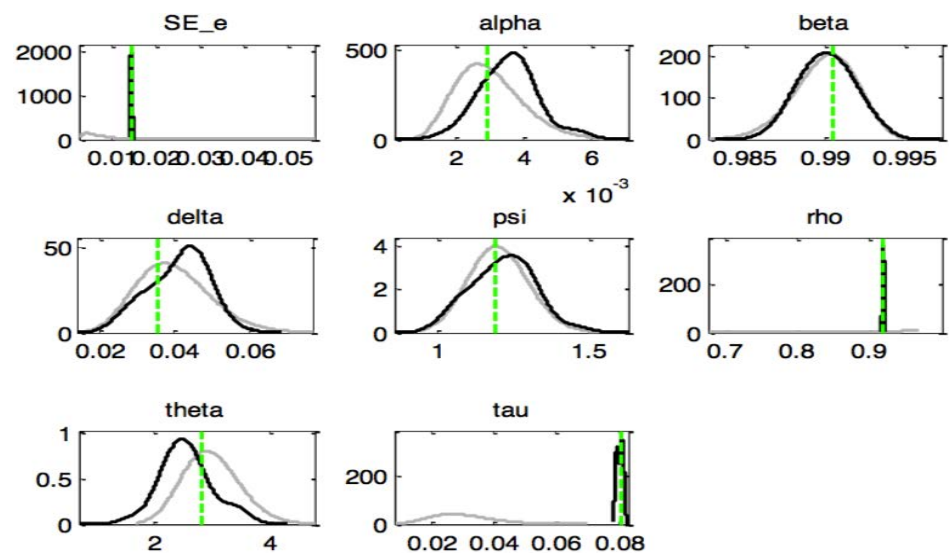

Figure 3: Priors and posteriors in recessing economy. 

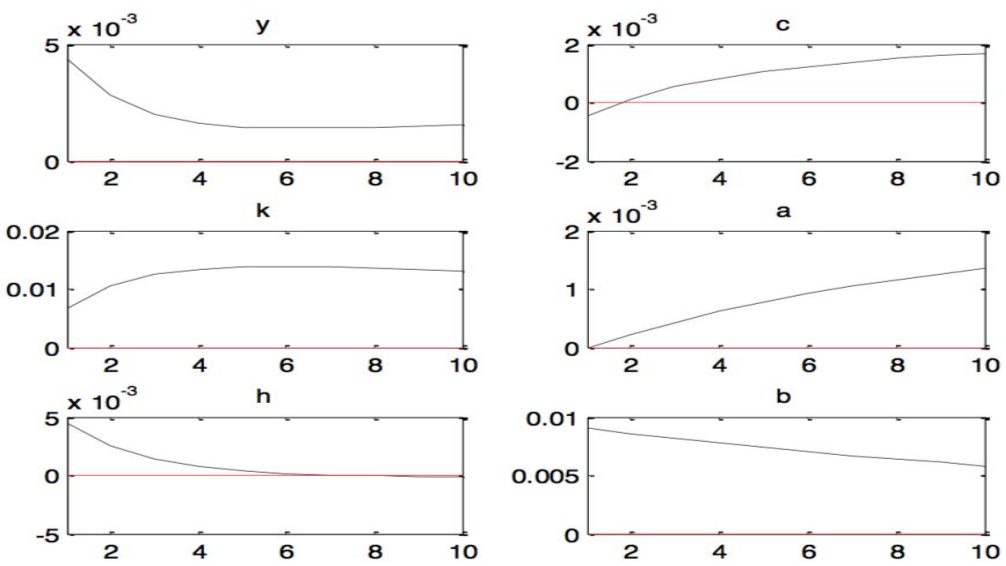

Figure 4: Speedy adjustment of structurally economic variables in normal economy.
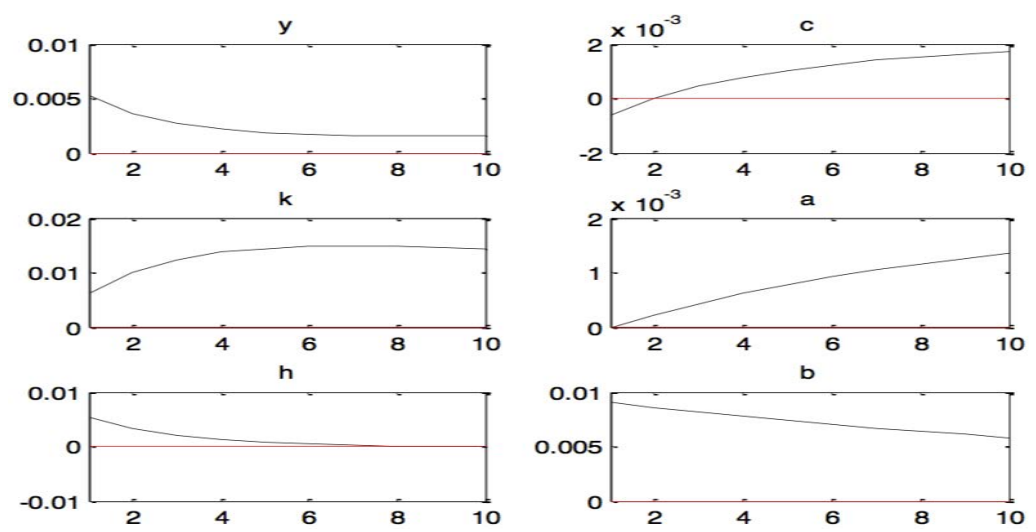

Figure 5: Speedy adjustment of structurally economic variables in boom economy.
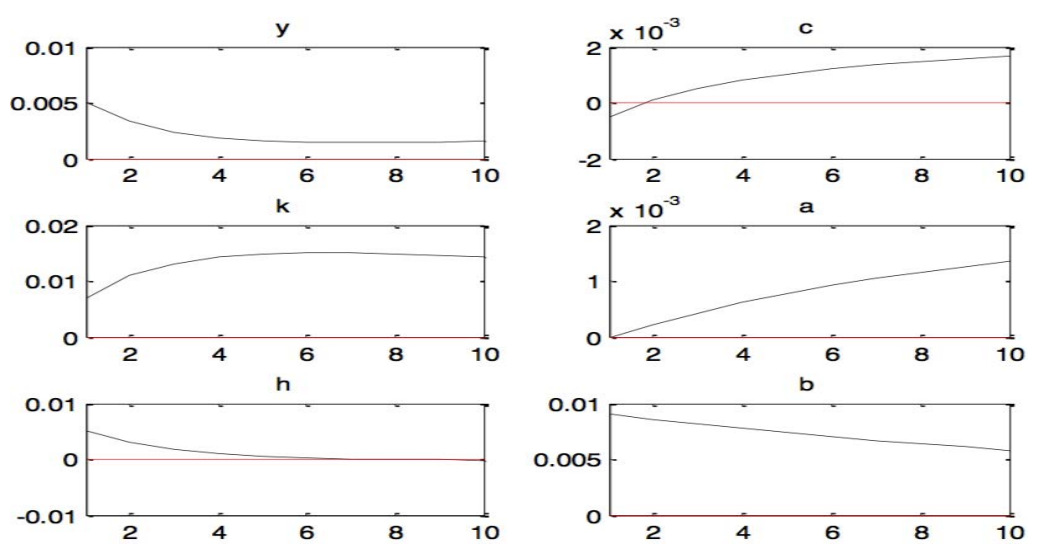

Figure 6: Speedy adjustment of structurally economic variables in recessing economy. 


\section{CONCLUSION}

One of the most complicated issues is the dynamic stochastic prediction of tourism incomes that affected the economic structure has been successfully clarified in this study. However, it is not the only part. This paper is proposed to statistically employed Bayesian inference to investigate evidences of the seasonal trends in Thailand tourism information as well as economic cycling adjustments in Thailand's economy. Empirically, seasonal unit-root conditions were indicated in collected data by comparing Bayes' factors. It could be implied that seasonally stationary testing should be mentioned rather than using the normal unit-root checking, and this strongly confirms that tourism in Thailand is not famous along the whole year. To address this issue, the sustainable tourism in all seasons must be considerably mentioned by long-staying travellers. Consequently, living-prices control and domestic traveling cost should be intensively taken into consideration by the government. Crucially, the images of dark tourism in Thailand must be erased from the tourists' perception.

The second approach is the MSBVAR approach. Based on the RBC model, the empirical findings show that there are fluctuated circumstances in Thailand tourism and economic cycling, including high-season and low-season periods. These outcomes evidently confirm that tourism policies should be considered parallel to the matter of time changing. The policy for controlling environmental impacts must be precisely launched in the booming situations. On the other hand, the driving policy should be creatively activated in the low-season cases.

The last econometric method is the BDSGE model and is highlighted for answering the dynamic prediction regarding the shocks from tourism revenues affecting the RBC parameters. The empirical results indicated that the effects from booming tourism periods have a positive relation to smooth the convergence of economic cycling parameters. This can be explained that there is no anxiety issue and the increments of tourism revenues lead to systematically boot up employments in economy. Tourism policies should be implemented for extending high-season moments as long as possible. On the other hand, the results showed the cases of low-seasonal periods negatively cause fluctuations in the economic system, especially the sudden shut down in labour sectors. Training programs for improving skilled labours in service sectors and technology adaptations should be intensively activated. Moreover, the variety of tourism such as MICE tourism, which is defined as tourism in meetings, incentive travels, conferences, and exhibitions, should be mentioned and implemented to encourage Thailand tourism to sustainably grow up.

\section{APPENDIX}

\section{The Bayesian HEGY Seasonal Unit Root Test (BHEGY test)}

From the Bayes' theorem, we obtain the posterior density $\pi(\theta \mid y)$ that refers to a probability distribution of parameters $\theta$ as Takaishi [4],

$$
\pi(\theta \mid y) \alpha L(y \mid \theta) \pi(\theta) .
$$

As shown in eqn (1), $\pi(\theta)$ is the prior density for $\theta$. Since the functional form of $\pi(\theta)$ is not known. This can be assumed to be constant, which is expressed in eqn (2):

$$
\{\theta\}=\frac{1}{Z} \int \theta \pi(y \mid \theta) \pi(\theta)
$$

and: 


$$
Z=\int \pi(\theta \mid y) d \theta
$$

From eqns (2) and (3), $\{\theta\}$ cannot be analytically performed. Bayesian modelling, as mentioned, requires a joint distribution, which is conveniently factored into a prior distribution for the parameters, and the complete-data likelihood function expressed in eqn (4) [13].

$$
L(y \mid \theta)=\prod_{i=1}^{n} \frac{1}{\sqrt{2 \pi \sigma_{t}^{2}}} \exp \left(-\frac{y_{t}^{2}}{2 \sigma_{t}^{2}}\right)
$$

where $y$ refers to the time-series data of n observations, $y=(y 1, y 2, \ldots y n)$ and $\theta$ stands for the estimated parameters. Considering eqn (4), the parameters in the log-likelihood function can be maximized expressed in eqn (5),

$$
\operatorname{LnL}(y \mid \theta)=-\frac{1}{2} \sum_{i}^{n} \ln \left(2 \pi \sigma_{t}^{2}\right)-\sum_{i}^{n} \frac{y_{t}^{2}}{2 \sigma_{t}^{2}}
$$

According to Kass and Raftery [14] and Chen et al. [15], Bayesian statistics considered hypotheses regarding to multiple parameters by adapting Bayes factor comparisons. The Bayes factors are flexible allowing multiple hypotheses to be a synchronized comparison, and nested models are not used in order to make comparisons [16]. Since it is obvious that time-series data of tourism trends has a seasonally structural movement. We perform the HEGY test introduced by Hylleberg et al. [6] and Shirvani et al. [17] and apply Bayesian analysis to determine the numbers of unit roots, which are relied on the following auxiliary regression,

$$
\Delta(B) y_{4, t}=\mu_{t}+\pi_{1} y_{1, t-1}+\pi_{2} y_{2, t-1}+\pi_{3} y_{3, t-2}+\pi_{4} y_{3, t-1}+\varepsilon_{t} .
$$

The Markov Switching Bayesian Vector Autoregressive (MSBVAR)

Historically, the journal paper of Hamilton [18] who introduced a Markov-switching autoregressive model to study on the quarterly data of US GNP, the Markov-switching version of Bayesian vector autoregressive model is conducted for breaking down normality assumptions in time series forecasting. The structural equation of Markov-switching Bayesian VAR (MS-BVAR) is described as

$$
\sum_{i=0}^{p} y_{t-1} M_{i}\left(s_{t}\right)=\delta\left(s_{t}\right)+\varepsilon_{t}\left(s_{t}\right), \quad t=1,2, \ldots, T
$$

Considering eqn (7), $S_{\mathrm{t}}=j$ is a h-dimensional vector state of the switching process, $j$ is the term of integer labels for the state, with a $\mathrm{h} \times \mathrm{h}$ Markov transition matrix. The matrix is given the probability of transitioning from the state $S_{\mathrm{t}-\mathrm{i}}$ to $S_{\mathrm{t}}$, which can be mathematically defined as $\operatorname{Pr}\left(S_{t}=k \mid S_{t-i}=j\right)$. For setting the prior in the MSBVAR model, the parameters $M_{\mathrm{i}}$ and $\delta$ are determined by sensible beliefs, the random walk prior in the Sims and Zha model [19]. 
Thus, the predictions from a Markov-switching VAR model like eqn (7) are the weighted combination of the forecasts for each state or phase.

\section{Bayesian Dynamic Stochastic General Equilibrium modelling (B-DSGE)}

In the process of the MCMC technique, the Metropolis algorithm introduced by Metropolis et al. [20], [21] is designed to estimate an integral such as eqn (2). In this paper, the BDSGE model is simplified as a standard Real Business Cycle model (RBC model) taken from Collard and Juillard [22] and Griffoli [23]. In other words, the economy cycle includes of an infinitely living representative agent who values consumption $C_{\mathrm{t}}$ and labour service $h_{\mathrm{t}}$, and this can be described as the utility function,

$$
U_{t} \sum_{\tau=t}^{\infty} \beta^{\tau-t}\left[\log \left(c_{t}\right)-\theta \frac{h_{t}^{1+\varphi}}{1+\varphi}\right]
$$

where the discount factor $0<\beta<1$, the disutility of tourism labours $\theta>0$ and the elasticity of labour supplies (tourism ratios to nominal GDP), is defined as $\varphi \geq 0$. To activate policies, a social planner optimizes this utility function subjected to the resource constraint, which is explained in eqn (9).

$$
c_{i}+i_{t}=y_{t}
$$

where $i_{\mathrm{t}}$ is investment and $y_{\mathrm{t}}$ is output. Consumers are owners of the firms. In a real economy, the output can be consumed and partly invested to the form of physical capital. Hence, the law of motions of capital is defined as

$$
k_{t+1}=\exp \left(b_{t}\right) i_{t}+(1-\delta) k_{t}
$$

where $b_{\mathrm{t}}$ is a shock affecting incorporated technological progress. Physical depreciation $\delta$ is expressed as $0<\delta<1$. Also, a standard constant return to scale is assumed to produce output. The form of the production function is given by,

$$
y_{t}=\exp \left(a_{t}\right) k_{t}^{\alpha} h_{t}^{1-\alpha}
$$

where $\alpha$ is the capital elasticity in the production function, with $0<\alpha<1$, and stands for a stochastic shock (or Solow residual). For describing a shock structure, shocks are allowed to display persistence across time and correlation in the recent period. This can be shown in eqn (12).

$$
\left\{\begin{array}{l}
a_{t} \\
b_{t}
\end{array}\right\}=\left\{\begin{array}{ll}
\rho & \tau \\
\tau & \rho
\end{array}\right\}\left\{\begin{array}{l}
a_{t-1} \\
b_{t-1}
\end{array}\right\}+\left\{\begin{array}{l}
\varepsilon_{t} \\
\mu_{t}
\end{array}\right\}
$$

where $|\rho+\tau|<1$ and $|\rho-\tau|<1$ to confirm stationary, we define $\rho$ is the coefficient of persistence and $\tau$ is the coefficient of cross persistence, and we assume $E_{t}\left(\varepsilon_{\mathrm{t}}\right)=0$ and $\operatorname{Et}\left(\mu_{\mathrm{t}}\right)$ $=0$ to be the contemporaneous variance-covariance matrix of the innovations $\varepsilon_{\mathrm{t}}$ and $\mu_{\mathrm{t}}$. 


\section{REFERENCES}

[1] Jaswal, S.S., Role of tourism industry in India's development. Journal of Tourism and Hospitality, 3(2), 2014.

[2] Knoema, Thailand - Travel \& Tourism Total Contribution to GDP. Retrieved from https://knoema.com/atlas/Thailand/topics/Tourism/Travel-and-Tourism-TotalContribution-to-GDP/Contribution-of-travel-and-tourism-to-GDP-percent-of-GDP, 2017.

[3] Mankiw, N.G., Real business cycles: A new Keynesian perspective. Journal of Economic Perspectives, 3(3), pp. 79-90, 1989.

[4] Takaishi, T., Bayesian inference with an adaptive proposal density for GARCH models. Journal of Physics: Conference Series, 221, 2010.

[5] Türkcan, S., Alexandrou, A. \& Masson, J.B., A Bayesian inference scheme to extract diffusivity and potential fields from confined single-molecule trajectories. Biophysical Journal, 102, pp. 2288-2298, 2012.

[6] Hylleberg, S., Engle, R.F., Granger, C.W.J. \& Yoo, B.S., Seasonal integration and cointegration. Journal of Econometrics, 44, pp. 215-238, 1990.

[7] Bildirici, M. \& Ersin, O., Modeling Markov Switching ARMA-GARCH neural networks models and an application to forecasting stock returns. The Scientific World Journal, 2014. http://dx.doi.org/10.1155/2014/497941.

[8] Chaitip, P. \& Chaiboonsri, C., Dependence modelling of Malaysian Ringgit (MYR) and Thai Baht (THB): The Markov switching model with dynamic copula approach (DCA) and bivariate extreme value approach. International Journal of Computational Economics and Econometrics, 6(2), pp. 138-155, 2016.

[9] Fernández-Villaverde, J., The econometrics of DSGE models. SERIEs, 1, pp. 3-49, 2010.

[10] Kliem, M. \& Uhlig, H., Bayesian estimation of a DSGE model with asset prices. Discussion Paper No. 37/2013. Deutsche Bundesbank, Germany, 2013.

[11] Tanboon, S., The bank of Thailand structural model for policy analysis. Discussion Paper. Bank of Thailand, 2008.

[12] Alp, H. \& Elekdag, S., Shock therapy! What role for Thai monetary policy? IMF Working Paper 12/269. Asia and Pacific Department, International Monetary Fund, 2012.

[13] Shalizi, C.R. \& Gelman, A. 2013. Philosophy and the practice of Bayesian statistics. British. Journal of Mathematical and Statistical Psychology, 66, pp. 8-38, 2013.

[14] Kass, R.E. \& Raftery, A.E., Bayes factors. Journal of the American Statistical Association, 90, pp. 773-795, 1995.

[15] Chen, C.W.S., Chen, S.Y. \& Lee, S., Bayesian unit root test in double threshold heteroskedastic models. Computational Economics, 42, pp. 471-490, 2013.

[16] Jeffreys, H., Theory of Probability (3rd ed.). Oxford University Press: New York, 1961.

[17] Shirvani, H., Wilbratte, B. \& Delcoure, N., Testing for periodic integration and cointegration of the stock prices of the G7 countries. Investment Management and Financial Innovations, 6(1-1), 2009.

[18] Hamilton, J., A new approach to the economic analysis of nonstationary time series and business cycle. Econometrica, 57(2), pp. 357-384, 1989.

[19] Sims, C.A. \& Zha, T.A., Bayesian methods for dynamic multivariate models. International Economic Review, 39(4), pp. 949-968, 1998.

[20] Metropolis, N. et al., Equations of state calculations by fast computing machines. Journal of Chemical Physics, 21, 1953. 
[21] Hastings, W.K., Monte Carlo sampling methods using Markov chains and their applications. Biometrika, 57, 1970.

[22] Collard, F. \& Juillard, M., Accuracy of stochastic perturbation methods: the case of asset pricing models. Journal of Economic Dynamics and Control, 25(6-7), pp. 979999, 2001.

[23] Griffoli, T.M., An Introduction to The Solution \& Estimation of DSGE Models. The Free Software Foundation, 2013. 